\title{
Detection of Hypertension-Induced Changes in Erythrocytes by SERS Nanosensors
}

\author{
Evelina I. Nikelshparg ${ }^{1, *}$, Adil A. Baizhumanov ${ }^{1}{ }^{(\mathbb{D}}$, Zhanna V. Bochkova ${ }^{1}$, Sergey M. Novikov ${ }^{2} \mathbb{D}^{\mathbb{B}}$, \\ Dmitry I. Yakubovsky ${ }^{2}$, Aleksey V. Arsenin ${ }^{2}{ }^{-}$, Valentyn S. Volkov ${ }^{2}{ }^{(D)}$, Eugene A. Goodilin ${ }^{3,4}$, \\ Anna A. Semenova ${ }^{3}$, Olga Sosnovtseva ${ }^{5}$, Georgy V. Maksimov ${ }^{1,6}{ }^{\circledR}$ and Nadezda A. Brazhe ${ }^{1, *}$
}

1 Department of Biophysics, Biological Faculty, Moscow State University, 119991 Moscow, Russia; adilbayzhumanov@biophys.msu.ru (A.A.B.); zh.bo4kova@yandex.ru (Z.V.B.); gmaksimov@mail.ru (G.V.M.)

2 Center for Photonics and 2D Materials, Moscow Institute of Physics and Technology (MIPT), 141700 Dolgoprudny, Russia; novikov.s@mipt.ru (S.M.N.); dmitrii.yakubovskii@phystech.edu (D.I.Y.); arsenin.av@mipt.ru (A.V.A.); vsv.mipt@gmail.com (V.S.V.)

3 Faculty of Materials Sciences, Moscow State University, 119991 Moscow, Russia; goodilin@yandex.ru (E.A.G.); semenovaAA@my.msu.ru (A.A.S.)

4 Department of Chemistry, Moscow State University, 119991 Moscow, Russia

5 Department of Biomedical Sciences, Faculty of Health and Medical Sciences, University of Copenhagen, 2200 Copenhagen, Denmark; olga@sund.ku.dk

6 Department of Physical Material Engineering, Federal State Autonomous Educational Institution of Higher Education "National Research Technological University "MISiS", 119049 Moscow, Russia

* Correspondence: nikelshparg.evelina.2010@post.bio.msu.ru (E.I.N.); nadezda.brazhe@biophys.msu.ru (N.A.B.)

check for updates

Citation: Nikelshparg, E.I.;

Baizhumanov, A.A.; Bochkova, Z.V.; Novikov, S.M.; Yakubovsky, D.I.; Arsenin, A.V.; Volkov, V.S.; Goodilin, E.A.; Semenova, A.A.; Sosnovtseva,

O.; et al. Detection of

Hypertension-Induced Changes in Erythrocytes by SERS Nanosensors. Biosensors 2022, 12, 32. https:// doi.org/10.3390/bios12010032

Received: 22 November 2021

Accepted: 5 January 2022

Published: 8 January 2022

Publisher's Note: MDPI stays neutral with regard to jurisdictional claims in published maps and institutional affiliations.

Copyright: (C) 2022 by the authors. Licensee MDPI, Basel, Switzerland. This article is an open access article distributed under the terms and conditions of the Creative Commons Attribution (CC BY) license (https:// creativecommons.org/licenses/by/ $4.0 /)$.

\begin{abstract}
Surface-enhanced Raman spectroscopy (SERS) is a promising tool that can be used in the detection of molecular changes triggered by disease development. Cardiovascular diseases (CVDs) are caused by multiple pathologies originating at the cellular level. The identification of these deteriorations can provide a better understanding of CVD mechanisms, and the monitoring of the identified molecular changes can be employed in the development of novel biosensor tools for early diagnostics. We applied plasmonic SERS nanosensors to assess changes in the properties of erythrocytes under normotensive and hypertensive conditions in the animal model. We found that spontaneous hypertension in rats leads (i) to a decrease in the erythrocyte plasma membrane fluidity and (ii) to a decrease in the mobility of the heme of the membrane-bound hemoglobin. We identified SERS parameters that can be used to detect pathological changes in the plasma membrane and submembrane region of erythrocytes.
\end{abstract}

Keywords: surface-enhanced Raman spectroscopy; hemoglobin; erythrocytes; plasma membrane; biosensing; nanoparticles; plasmonic nanostructures; spontaneously hypertensive rats

\section{Introduction}

The development of novel methods and techniques has expanded our understanding of the molecular mechanisms underlying many pathologies and paved the way for the creation of novel diagnostic tools [1-3]. Cardiovascular diseases remain the leading cause of death around the world. High blood pressure is one of the most important risk factors for cardiovascular diseases, leading to organ hypoxia and consequent damage, such as heart failure, stroke, vasculopathy, and nephropathy [4-6]. Hypoxic conditions can develop as the result of hypertension-induced alterations in vessel structure and hemodynamics [4,7]. Another cause of tissue hypoxia is abnormal changes in hemoglobin's $(\mathrm{Hb})$ affinity for oxygen $\left(\mathrm{O}_{2}\right)$, leading to the decreased rate of $\mathrm{Hb}$ saturation with $\mathrm{O}_{2}$ in the lungs or to the decreased ability of $\mathrm{Hb}$ to release $\mathrm{O}_{2}$ in peripheral tissues. Thus, the fine tuning of $\mathrm{Hb}$ properties ensures the optimal supply of $\mathrm{O}_{2}$ to tissue $[8,9]$. 
Surface-enhanced Raman spectroscopy (SERS) has been successfully applied to detect different disease biomarkers in blood and other body fluids $[3,10,11]$. We have proposed an approach for the selective study of the $\mathrm{Hb}_{\mathrm{mb}}$ in erythrocytes with SERS using a colloidal solution of silver nanoparticles [12] and silver nanostructured surfaces (AgNSS) [13,14]. Plasmonic nanostructures allow us to achieve the enhancement of the Raman scattering from molecules near the nanostructure surface. In the case of erythrocytes, this occurs from membrane-bound $\mathrm{Hb}\left(\mathrm{Hb}_{\mathrm{mb}}\right)$ bound to AE1-exchanger (also known as band 3 protein). Erythrocyte plasma membrane lipids can be probed simultaneously [15]. Conventional Raman spectroscopy allows one to assess the degree of oxygenation, the conformation, and the affinity of the heme to $\mathrm{O}_{2}$ of cytosolic $\mathrm{Hb}\left(\mathrm{Hb}_{\mathrm{c}}\right)$ in intact erythrocytes. However, it fails to probe $\mathrm{Hb}_{\mathrm{mb}}$, a minor fraction of $\mathrm{Hb}$, which is more sensitive to oxidative stress, changes in plasma membrane properties, and ion transport through the membrane than $\mathrm{Hb}_{\mathrm{c}}[16,17]$.

In the present work, we employed SERS with AgNSS to study the effect of spontaneous hypertension on the properties of the plasma membrane and membrane-bound hemoglobin in erythrocytes. The proposed approach is able to detect changes in erythrocyte properties in the early stages of hypertension, such as a decrease in the erythrocyte plasma membrane fluidity and a decrease in the $\mathrm{Hb}_{\mathrm{mb}}$ heme mobility.

\section{Materials and Methods}

\subsection{Nanostructure Synthesis}

The preparation of AgNSS was performed as described in References [13,18] with modifications. Briefly, $0.3 \mathrm{~g}$ of silver nitrate (Sigma, Schnelldorf, Germany, 99.999\% purity) was dissolved in $40 \mathrm{~mL}$ of MilliQ water under constant stirring, followed by the addition of $30 \mathrm{~mL}$ of $20 \% \mathrm{NaOH}$ solution. The resulting dark precipitate of silver oxide (I) was washed three times with $100 \mathrm{~mL}$ of MilliQ water, followed by the addition of $5 \mathrm{~mL}$ of $25 \%$ aqueous ammonia and $25 \mathrm{~mL}$ of MilliQ water, resulting in transparent precursor solution of diamine silver (I) hydroxide. Albedo ultrasonic nebulizer was used to spray the obtained solution of silver complex onto the surface of coverslips placed inside $1000 \mathrm{~mL}$ glass on a surface heated up to $340{ }^{\circ} \mathrm{C}$ (IKA C-MAG HS 4) for an hour with 5 min breaks every 3-4 min. The coverslips with a silver nanostructured layer were kept at $340{ }^{\circ} \mathrm{C}$ for $15 \mathrm{~min}$ after the completion of spraying to decompose and desorb possible residual intermediate compounds.

\subsection{Characterization of Nanostructures}

The fabricated AgNSS were visualized by a scanning electron microscope (SEM) NVision 40 (Carl Zeiss). The near-field optical characterization was performed by scatteringtype scanning near-field optical microscope s-SNOM "NeaSNOM" (Neaspec, Munich, Germany) based on an atomic force microscope that uses sharp silicon tips covered with a Pt-Ir coating as a near-field probe. The scanning was carried out in a tapping mode with an oscillation frequency of $\sim 250 \mathrm{kHz}$. The tip-sample interface was illuminated under $\sim 50^{\circ}$ relative to the sample surface by a linearly P-polarized Avesta TiC, Ti:Sapphire continuous tunable laser (700-1000 nm). In this s-SNOM setup, the laser beam is focused on the nanostructures by an upper parabolic mirror. A tip-scattered near-field signal is collected by the same parabolic mirror and goes to a high-sensitive detector, then analyzed after.

\subsection{Animals}

Male 15- or 16-week-old rats from two strains (3 rats in each group) were used in the experiments: spontaneously hypertensive rats (SHR), and Wistar-Kyoto rats (WKY) (BIBCh, Pushchino, Russia). The animal studies were carried out in accordance with the Declaration of Helsinki, EU Directive 2010/63/EU, and the Recommendations of the European Laboratory Animal Science Associations 2014 (FELASA), after permission was granted by the Bioethics Committee of Moscow State University (protocol №82-O, 08.06.2017). 
Arterial blood pressure (ABP) was measured noninvasively using the photoelectric plethysmography technique [19] at least 3 times for each rat after adaptation and handling. For WKY rats, the ABP was $139 \pm 4 \mathrm{~mm} \mathrm{Hg}$; for SHR rats, the ABP was $203 \pm 4 \mathrm{~mm} \mathrm{Hg}$.

\subsection{Preparation of Erythrocyte Ghosts}

Blood was collected during the decapitation of rats in $15 \mathrm{~mL}$ glass tubes containing heparin (10 units $/ \mathrm{mL}$ ). Erythrocyte ghosts (enclosed vesicles consisting of erythrocyte plasma membrane with membrane-bound hemoglobin $\left(\mathrm{Hb}_{\mathrm{mb}}\right)$ and submembrane cytoskeleton without cytosolic $\mathrm{Hb}$ ) were obtained as described in Reference [12]. Briefly, red blood cell mass was hemolyzed in 20 volumes of phosphate buffer $\left(4.7 \mathrm{mM} \mathrm{Na}_{2} \mathrm{HPO}_{4}, 0.3 \mathrm{mM} \mathrm{NaH}_{2}\right.$ $\mathrm{PO}_{4}(\mathrm{pH} 7.4), 4^{\circ} \mathrm{C}$ ), followed by three washings and centrifugations ( $\left.3500 \mathrm{~g}, 40 \mathrm{~min}\right)$. The erythrocyte ghosts were concentrated by centrifugation (13000 g, $40 \mathrm{~min})$.

\subsection{SERS Measurements}

SERS measurements were performed using an InVia Raman microscope (Renishaw, New Mills, Wotton-under-Edge, Gloucestershire, United Kingdom) equipped with a $20 \mathrm{~mW}$ $514 \mathrm{~nm}$ argon laser and power neutral density filter (50\%). All the spectra were collected using a $20 \times$ NA 0.4 objective and $20 \mathrm{~s}$ acquisition time. Laser power was 1-5 mM per registration spot. A silicon wafer was used for calibration. The SERS spectra of erythrocytes and erythrocyte ghosts were registered as described previously [12,14]. Before the SERS measurements, suspensions of erythrocyte ghosts were diluted 5 times with the Alen saline $\left(145 \mathrm{mM} \mathrm{NaCl}, 5 \mathrm{mM} \mathrm{KCl}, 4 \mathrm{mM} \mathrm{Na} \mathrm{HPO}_{4}, 1 \mathrm{mM} \mathrm{NaH} \mathrm{PO}_{4}, 1 \mathrm{mM} \mathrm{MgSO}\right.$, $1 \mathrm{mM} \mathrm{CaCl}$, $\mathrm{pH}$ 7.4). To perform SERS measurements, $300 \mu \mathrm{L}$ of the suspension of interest were dropped on the AgNSS placed into a glass-bottom Petri dish, then SERS spectra were collected from several places.

\subsection{SERS Spectra Analysis and Statistics}

SERS spectra were processed using open source software Pyraman available at https: / / github.com/abrazhe/pyraman accessed on 22 November 2021. The baseline was subtracted in each spectrum and ratios of peaks intensities $\mathrm{I}_{1638} / \mathrm{I}_{1375}, \mathrm{I}_{1175} / \mathrm{I}_{1375}$ and $\mathrm{I}_{2872} / \mathrm{I}_{2927}$ were calculated after the baseline substraction.

Statistical data were analyzed using GraphPad Prism 8.4 (https: / / www.graphpad. com accessed on 22 November 2021). The Mann-Whitney U test was used for group comparisons.

\section{Results}

\subsection{Experimental Design and AgNSS Characterization}

Hypertension-related effects were studied in two types of samples obtained from the blood of hypertensive and normotensive rats: on diluted suspensions of erythrocytes and diluted suspensions of erythrocyte ghosts (Figure 1a).

Erythrocyte ghosts serve as a simplified experimental model of the submembrane region of erythrocytes, since they represent enclosed vesicles of the erythrocyte plasma membrane with $\mathrm{Hb}_{\mathrm{mb}}$, which maintains its interaction with AE1-exchanger [20,21] (Figure 1b). The submembrane region of intact erythrocytes is more complicated and consists of the plasma membrane, $\mathrm{Hb}_{\mathrm{mb}}$ interacting with the AE1-exchanger, and the cytoskeleton with some amount of $\mathrm{Hb}_{\mathrm{c}}$ in close vicinity to the inner membrane surface (Figure $1 \mathrm{~b}$ ). To record SERS spectra from molecules in the submembrane region of the studied preparations a small volume of the diluted erythrocyte or erythrocyte ghost suspension was placed on plasmonic nanostructured surfaces (AgNSS in a glass Petri dish). The AgNSS, which were formed by the ultrasonic spraying method [13], have a complex morphology of intersecting circles consisting of silver nanoparticles of different sizes from 5-20 nm up to $100 \mathrm{~nm}$ (Figure 2a). 
(a)

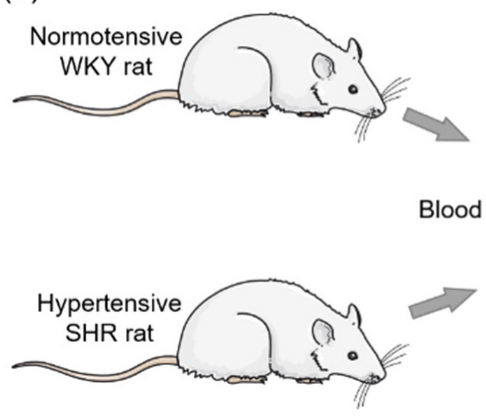

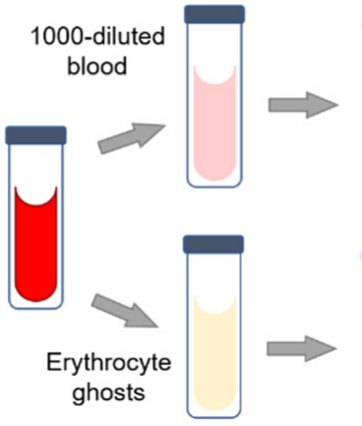

(b)

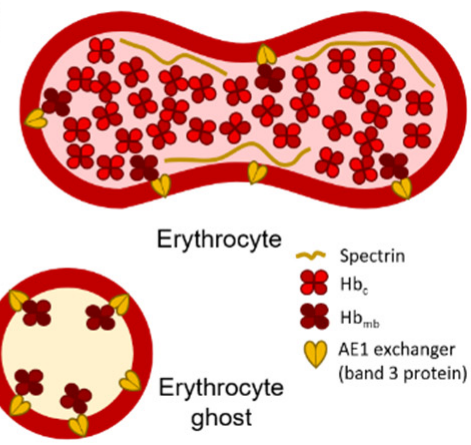

Figure 1. Schematic illustration of (a) the experimental design and (b) cross-sections of an erythrocyte and an erythrocyte ghost demonstrating the non-homogeneity of hemoglobin molecules in the submembrane region of erythrocytes and the homogeneity of hemoglobin bound to AE1-exchanger in erythrocyte ghosts-enclosed vesicles of erythrocyte plasma membrane.
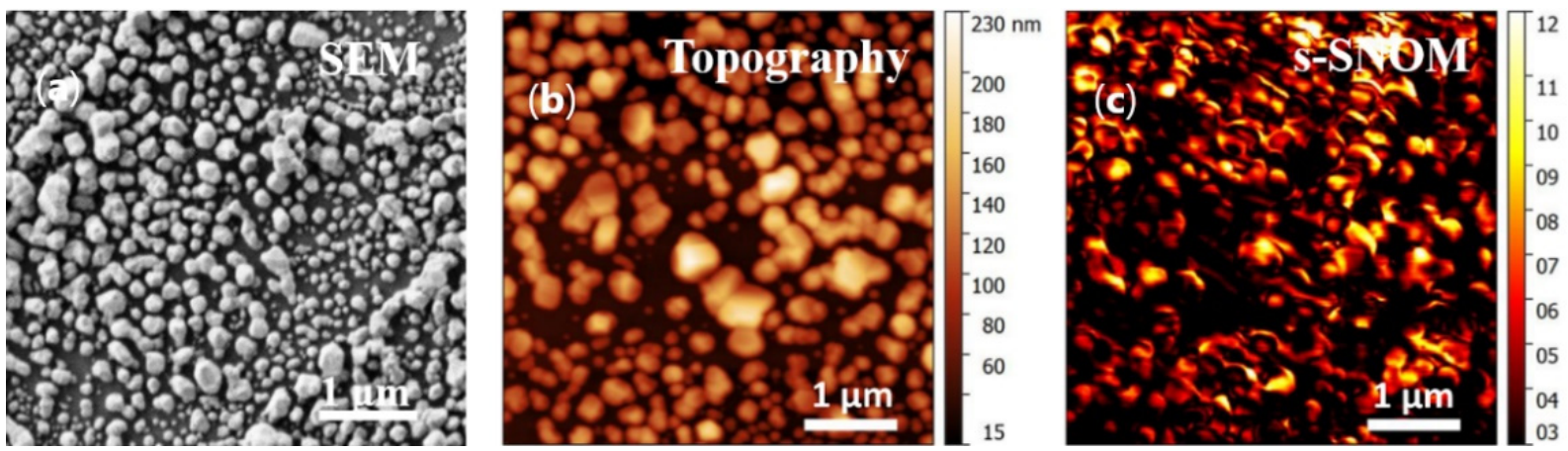

Figure 2. Characterization of plasmonic nanostructured surfaces. (a) SEM image of AgNSS; (b) topographical (AFM) image of AgNSS aggregates; (c) typical pseudo-color s-SNOM image $\left(5 \times 5 \mu \mathrm{m}^{2}\right)$ of Ag nanoparticles obtained at the wavelength $\lambda=720 \mathrm{~nm}$. The color scale (c) shows the optical near-field intensity in arbitrary units.

These nanostructures provide a stable and reproducible SERS signal from purified biomolecules, erythrocytes, and mitochondria, as was demonstrated in our previous works $[13,18]$. Thus, we have already demonstrated the reproducible SERS spectra from $\mathrm{Hb}_{\mathrm{mb}}$ in erythrocytes and cytochrome $c$ in mitochondria recorded from various places on the same AgNSS or from different AgNSS. We also showed the stability of SERS spectra of erythrocytes and mitochondria registered from the same region of AgNSS in time proving the absence of AgNSS degradation in the sample and the absence of the erythrocyte or mitochondria damage by nanostructures [13,18].

Before SERS measurements, the AgNSS were characterized by s-SNOM to visualize the light-sample interaction. The s-SNOM image (Figure 2c) revealed the existence of randomly distributed and strongly localized electromagnetic excitations-hot spots [22,23] that originate mainly due to the gaps between conglomerations of Ag nanoparticles. The comparative analysis of the s-SNOM image (recorded at $\lambda=720 \mathrm{~nm}$ ) was performed by directly superimposing one on the corresponding topographical image obtained for a typical conglomeration of Ag nanoparticles (Figure 2b,c). The localization of several hot spots can be clearly seen inside the conglomeration; their appearance should be directly attributed to the gaps between individual Ag nanoparticles. The wavelength used for s-SNOM characterization $(\lambda=720 \mathrm{~nm})$ is far from the $514 \mathrm{~nm}$ argon laser that was used in the SERS experiments. However, this is justified since gap-induced field enhancements are associated with the boundary conditions for the electric field [24-26] and therefore weakly depend on the excitation wavelength. Such places on AgNSS with high local electric fields ensure the enhancement of Raman scattering from molecules that are localized not only 
on the AgNSS, but also on some distance from nanoparticles (e.g., all $\mathrm{Hb}$ molecules in the submembrane region of erythrocytes and $\mathrm{Hb}_{\mathrm{mb}}$ in erythrocyte ghosts).

\subsection{Spontaneous Hypertension Affects Conformation of Heme in Hb Bound to AE1-Exchanger}

The SERS spectra of erythrocytes and erythrocyte ghosts recorded in low-frequency region (600-1800 $\left.\mathrm{cm}^{-1}\right)$ originate mainly from the heme molecules of oxyhemoglobin $(\mathrm{oHb})$ (Figure 3a) [12]. The oxygenation of all hemoglobin molecules in studied samples occurred during the high dilution of blood in erythrocyte suspension and during the procedure of ghost preparation. The complete oxygenation of $\mathrm{Hb}$ is attributed to SERS peaks that are sensitive to the $\mathrm{Hb}$ oxygenation state: the combination of intensive peaks at 1375,1585 , and $1638 \mathrm{~cm}^{-1}$ is the signature of $\mathrm{oHb}$, whereas peaks assigned to deoxyhemoglobin $(1355,1555$, and $\left.1606 \mathrm{~cm}^{-1}\right)$ and methemoglobin $\left(1360-1365,1565,1603 \mathrm{~cm}^{-1}\right)$ are absent [16,27-29]. The peaks at 1638 and $1585 \mathrm{~cm}^{-1}$ correspond to vibrations of methine bridges; the peaks at 1375 and $1175 \mathrm{~cm}^{-1}$ correspond to symmetric and asymmetric vibrations of pyrrole half rings, respectively; the peak at $1123 \mathrm{~cm}^{-1}$ reflects methyl group vibrations. The SERS spectra of erythrocytes and erythrocyte ghosts were stable over time and reproducible for different AgNSSs or different spots on the same region. Figure S1a (Supporting Information) demonstrates SERS spectra of erythrocyte ghosts recorded from three different regions of AgNSS. It can be seen that the spectrum structure and the input of main peaks into the overall spectrum are similar for all the SERS spectra. The same reproducibility was demonstrated with $\mathrm{Hb}_{\mathrm{mb}}$ in erythrocytes in our previous work [13], showing the absence of the negative effect of the biological sample on AgNSS and vice versa. An important parameter that is usually used to characterize SERS structures is the enhancement factor (EF). EF is calculated from concentrations of the molecule, giving Raman and SERS spectra and the peak intensities of a chosen peak in Raman and SERS spectra. Figure S1b (Supporting Information) demonstrates the Raman and SERS spectra of erythrocytes with a description of the EF calculation for the peak at $1638 \mathrm{~cm}^{-1}$ estimated to be $\approx 2.5 \times 10^{4}$.

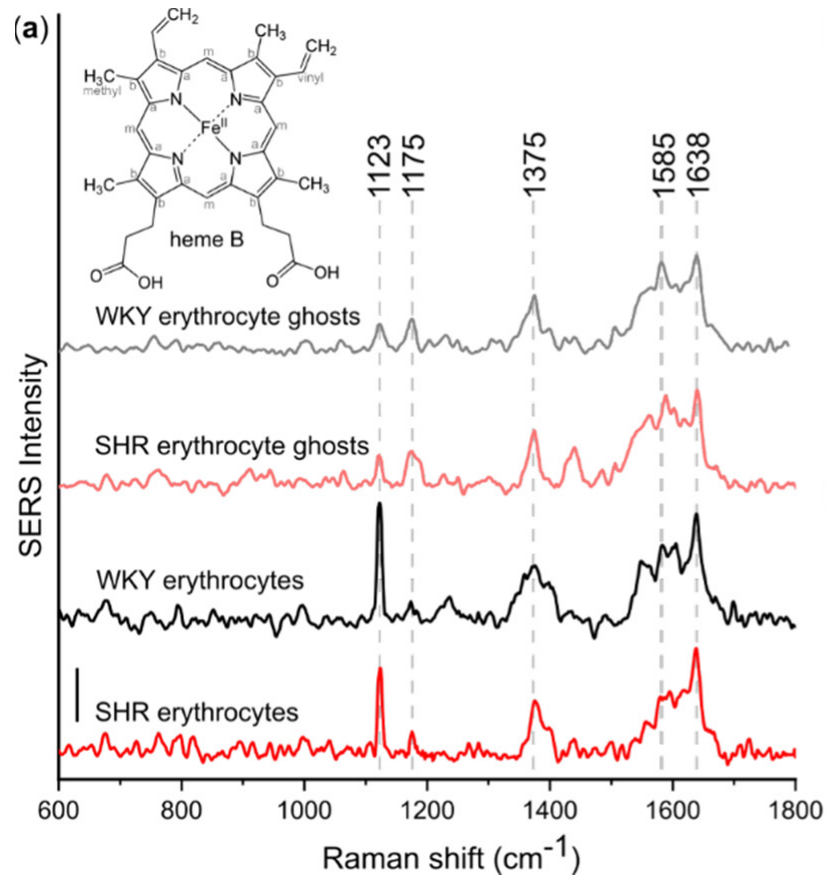

(b)

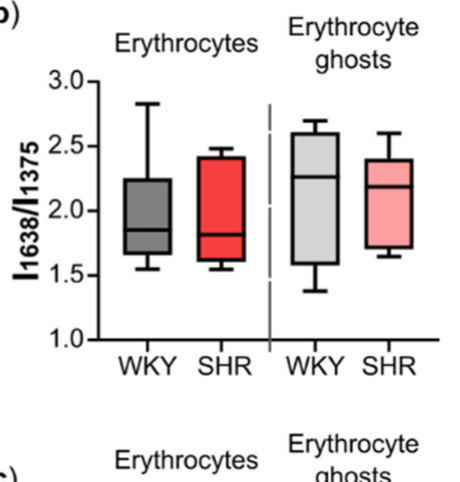

(c)

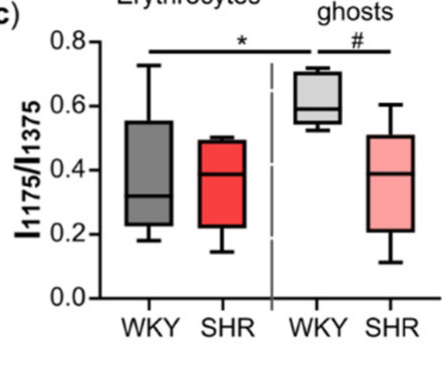

(d)
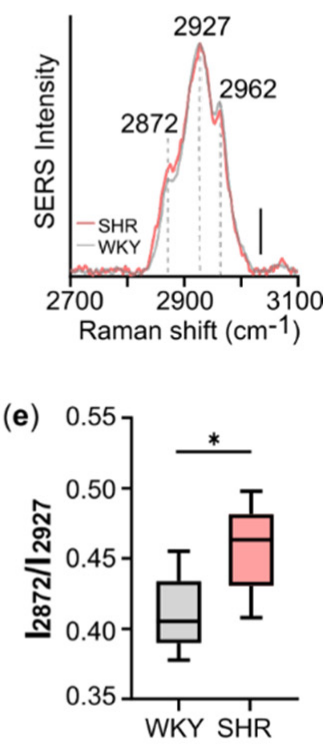

Figure 3. Hypertension-related effects. (a) SERS spectra of erythrocyte ghosts and erythrocytes from WKY rats and SHR in the low-frequency region. Spectra are normalized by the intensity of the peak at $1375 \mathrm{~cm}^{-1}$. Spectra are shifted vertically for a better presentation. Numbers above peaks correspond to the peak positions (in $\mathrm{cm}^{-1}$ ). Scale 0.5 a. u. (b) The ratio $\mathrm{I}_{1638} / \mathrm{I}_{1375}$ (the probability of the planar heme conformation) and (c) the ratio $\mathrm{I}_{1175} / \mathrm{I}_{1375}$ (in-plane heme mobility) calculated from the SERS 
spectra of erythrocytes and erythrocyte ghosts from WKY rats (grey boxes) and SHR (red boxes). * $p<0.05$; \# $p=0.0556$ (Mann-Whitney test). (d) SERS spectra of erythrocyte ghosts from WKY rats (gray) and SHR (red) in the high-frequency region. Spectra are normalized by the intensity of the peak $2927 \mathrm{~cm}^{-1}$. Numbers above peaks correspond to the peak positions (in $\mathrm{cm}^{-1}$ ). Scale $0.2 \mathrm{a}$. $\mathrm{u}$. (e) The ratio $\mathrm{I}_{2872} / \mathrm{I}_{2927}$ reflects the ordering of the lipid phase in the membrane of erythrocyte ghosts. * $p<0.05$ (Mann-Whitney test).

To investigate the conformational properties of $\mathrm{Hb}_{\mathrm{mb}}$ heme, we calculated the ratios of the SERS peak intensities: $\mathrm{I}_{1638} / \mathrm{I}_{1375}$ and $\mathrm{I}_{1175} / \mathrm{I}_{1375}$ (Figure $3 \mathrm{~b}, \mathrm{c}$ ). The intensity of the peak at $1375 \mathrm{~cm}^{-1}$ is used as a normalizing factor, since its intensity does not depend on the heme conformation and can be regarded as a constant value in our experimental conditions. As was demonstrated earlier [30-32], the heme $b$ in $\mathrm{Hb}$ predominantly exists in two conformations: planar and domed [30-32]. The first ratio, $\mathrm{I}_{1638} / \mathrm{I}_{1375}$, shows the probability of the planar heme conformation. The higher this ratio is, the higher the probability of a planar conformation of the heme is [33,34]. Moreover, the use of ratios of peak intensities causes the spectral analysis to be independent of the local SERS signal intensity. Our results clearly indicate the absence of the effect of hypertension on the probability of the planar heme conformation (Figure $3 b$ ). The ratio of $\mathrm{I}_{1175} / \mathrm{I}_{1375}$ peak intensities represents the probability of the asymmetric pyrrole half-ring vibrations and can be used as a marker of heme mobility: the higher this ratio is, the higher the in-plane mobility of the heme is $[33,34]$. We found that this ratio is more dispersed in erythrocytes than in erythrocyte ghosts (Figure 3c), which may be explained by the more heterogeneous $\mathrm{Hb}$ population in the submembrane region of intact erythrocytes than in erythrocyte ghosts (Figure $1 b$ ). We observed no differences in the $\mathrm{I}_{1175} / \mathrm{I}_{1375}$ ratio in the SERS spectra of erythrocytes from normotensive and hypertensive rats (Figure $3 \mathrm{c}$ ). In contrast, we observed a significant decrease in this ratio for erythrocyte ghosts from SHR rats, indicating the decreased in-plane mobility of the heme in $\mathrm{Hb}_{\mathrm{mb}}$ (Figure 3c). Moreover, this marker negatively correlates with ABP (Figure 4).

(a)

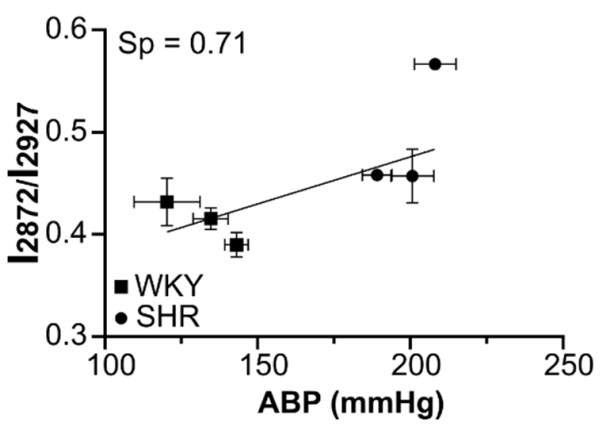

(c)

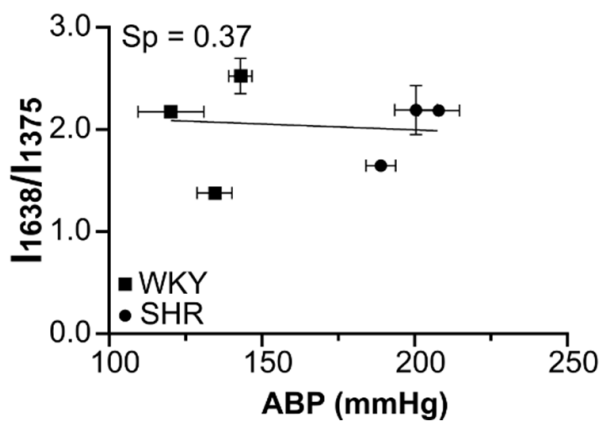

(b)

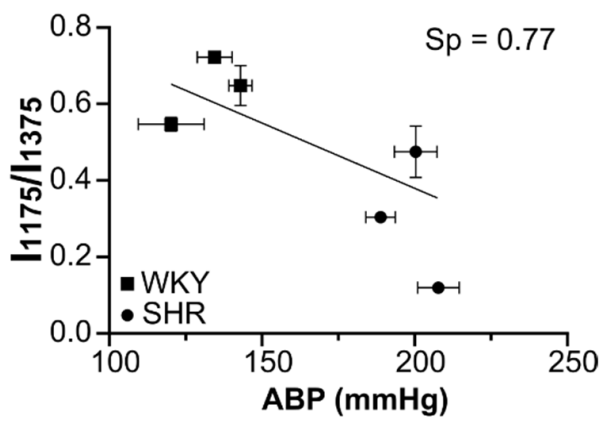

(d)

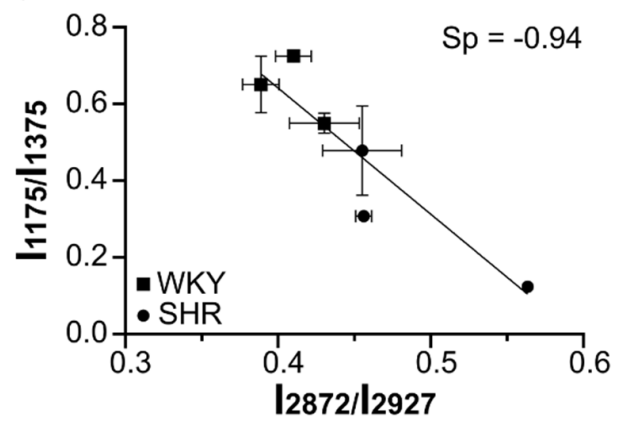

Figure 4. Correlations between different SERS parameters. (a-c) Correlations between arterial blood pressure (ABP) ( $x$-axis) and the ratios ( $y$-axis) of peak intensities in the SERS spectra of erythrocyte 
ghosts from WKY (squares) and SHR (circles) rats. (d) Correlation between the ratios corresponding to in-plane $\mathrm{Hb}$ heme mobility and the stiffness of plasma membrane of erythrocyte ghosts. Sp, Spearman correlation coefficient.

\subsection{Decreased Fluidity of Plasma Membrane of Erythrocytes under Spontaneous Hypertension}

To study the properties of the erythrocyte plasma membrane, we recorded SERS spectra in the high-frequency region $\left(2700-3100 \mathrm{~cm}^{-1}\right)$ from erythrocyte ghosts. The SERS spectra of erythrocyte ghosts contain three main peaks at 2872,2927 , and $2962 \mathrm{~cm}^{-1}$ (Table 1, Figure 3d), corresponding to $=\mathrm{CH}_{2}$ asymmetric, $=\mathrm{CH}_{2}$ symmetric, and $-\mathrm{CH}_{3}$ group vibrations, respectively [35]. These peaks are known to originate from lipids and proteins. In intact erythrocytes, the submembrane region contains different proteins; therefore, we did not record the SERS spectra of intact erythrocytes. In erythrocyte ghosts, lipids are the main component of the membrane region with the only subpopulation of $\mathrm{Hb}$ molecules bound to the AE1 protein. Thus, the SERS peaks at 2872, 2927, and $2962 \mathrm{~cm}^{-1}$ are assumed to originate mainly from lipids [15]. The ratio $\mathrm{I}_{2872} / \mathrm{I}_{2927}$ may indicate the ordering of the lipid phase. An increase in this ratio indicates an increase in the number of lipids in trans conformation, which make membrane less fluid [36]. We propose the use of the ratio $\mathrm{I}_{2872} / \mathrm{I}_{2927}$ to evaluate the fluidity of the erythrocyte ghost membrane (Figure 3e). The observed increase in this ratio indicates a decrease in the membrane fluidity. This ratio is statistically significantly higher in SHR rats (Figure 3e), or rats with elevated ABP. This means that spontaneous hypertension leads to the changes in lipid ordering and fluidity in the plasma membrane of erythrocytes.

Table 1. SERS peak assignment $[12,27,28,36]$.

\begin{tabular}{|c|c|c|}
\hline Peak Position $\left(\mathrm{cm}^{-1}\right)$ & Assignment & Main Contribution from Molecules: \\
\hline 1121 & $\mathrm{C}_{\mathrm{b}}-\mathrm{CH}_{3}$ & $\mathrm{HbO}_{2}$ \\
\hline 1175 & Pyrrole half-ring, asymmetric & $\mathrm{HbO}_{2}$ \\
\hline 1375 & Pyrrole half-ring, symmetric & $\mathrm{HbO}_{2}$ \\
\hline 1638 & $\mathrm{C}_{\mathrm{a}} \mathrm{C}_{\mathrm{m}}, \mathrm{C}_{\mathrm{a}} \mathrm{C}_{\mathrm{m}} \mathrm{H}, \mathrm{C}_{\mathrm{a}} \mathrm{C}_{\mathrm{b}}$ & $\mathrm{HbO}_{2}$ in planar conformation \\
\hline 2872 & $v_{\mathrm{as}}\left(=\mathrm{CH}_{2}\right)$ & $\begin{array}{l}\text { lipids in trans conformation and } \\
\text { cholesterol }\end{array}$ \\
\hline 2927 & $v_{\mathrm{s}}\left(-\mathrm{CH}_{3}\right)$ & lipids and proteins \\
\hline 2962 & $v_{\text {as }}\left(-\mathrm{CH}_{3}\right)$ & lipids and proteins \\
\hline
\end{tabular}

We also found that the ratio $\mathrm{I}_{2872} / \mathrm{I}_{2927}$ (lipid ordering marker) positively correlates with arterial blood pressure (ABP) in rats (Figure $4 \mathrm{a}$ ), whereas the ratio $\mathrm{I}_{1175} / \mathrm{I}_{1375}$ (reflecting the in-plane mobility of pyrrole half rings in a $\mathrm{Hb}_{\mathrm{mb}}$ heme) negatively correlates with $\mathrm{ABP}$ (Figure $4 \mathrm{~b}$ ). There is no correlation between the ratio $\mathrm{I}_{1638} / \mathrm{I}_{1375}$ (the probability of the planar conformation of $\mathrm{a} \mathrm{Hb}_{\mathrm{mb}}$ heme) and $\mathrm{ABP}$ (Figure $4 \mathrm{c}$ ). We notice that there is a strong negative correlation between the ratios $\mathrm{I}_{1175} / \mathrm{I}_{1375}$ and $\mathrm{I}_{2872} / \mathrm{I}_{2927}$, showing that the in-plane heme mobility in $\mathrm{Hb}_{\mathrm{mb}}$ decreases with the decrease in the plasma membrane fluidity.

\section{Discussion}

We applied plasmonic SERS nanostructures to study the properties of the membranebound hemoglobin and plasma membrane of erythrocytes and erythrocyte ghosts received from rats with normal and elevated arterial blood pressure. Our results revealed hypertension-induced changes in erythrocyte properties at the molecular level.

It should be noted that high requirements are imposed on SERS nanosensors for biological application-first of all, the reproducibility and stability of the Raman enhancement [37]. The SERS nanosensors used in this study proved themselves to be resistant to the biological preparations and have shown the ability to provide reproducible SERS spectra for a variety of biological objects $[13,15,18]$. Calculating the ratios of specified SERS peak intensities 
rather than analyzing absolute peak intensities helps to avoid the influence of variation in signal intensity on the interpretation of the results.

We used the ratio of SERS peak intensities $\mathrm{I}_{2872} / \mathrm{I}_{2927}$ to study the microfluidity of erythrocyte plasma membranes. We revealed decreased membrane fluidity in erythrocyte ghost membranes from hypertensive rats (SHR) compared to healthy normotensive rats (WKY) (Figure 3e), which fits well with clinically relevant data [38].

One of the explanations of this phenomenon is the increased level of cholesterol. An increased level of cholesterol in erythrocyte membranes from people with hypertension and other CVD was shown by Raman spectroscopy and EPR [38,39] and commercial enzymatic assays [40,41]. Increasing cholesterol leads to a decrease in membrane fluidity $[42,43]$ and changes in the erythrocyte function [44]. The SERS ratio $\mathrm{I}_{2872} / \mathrm{I}_{2927}$ was proposed as a marker of cholesterol amount by Faried et al. [45]. Thus, an increase in this ratio, indicating an increase in the membrane stiffness, may be explained by an increased amount of cholesterol in the erythrocyte plasma membrane.

For the first time, we observed a decrease in the in-plane mobility of heme in $\mathrm{Hb}$ bound to AE1-exchanger in hypertensive rats (Figure 3c), which is impossible to detect by other methods. Other powerful techniques such as photoacustics and NIRS $[46,47]$ allow determining only $\mathrm{Hb}_{\mathrm{c}}$ oxygenation, but not other properties. Raman spectroscopy is able to evaluate oxygenation, the affinity of $\mathrm{Hb}$ to oxygen, and the conformational properties of $\mathrm{Hb}_{\mathrm{c}}$, but not $\mathrm{Hb}_{\mathrm{mb}}$.

We suggest that the detected changes in $\mathrm{Hb}_{\mathrm{mb}}$ can be explained by the increasing stiffness of the membrane (Figure $4 \mathrm{~d}$ ), which leads to a reduction in the mobility of AE1exchanger [48], which in turn directly interacts with $\mathrm{Hb}_{\mathrm{mb}}$ and may affect the conformation and mobility of $\mathrm{Hb}_{\mathrm{mb}}$ globin. This may reduce the ability of a heme to adapt to changing oxygen concentrations and, thus, to disturb the normal functioning of $\mathrm{Hb}_{\mathrm{mb}}$ and impair oxygen supply to tissues in hypertensive conditions.

\section{Conclusions}

The use of SERS plasmonic nanosensors allowed us to detect hypertension-induced changes in the plasma membrane and in the conformation of heme in membrane-bound $\mathrm{Hb}$ in erythrocytes and erythrocyte ghosts. We revealed a decrease in erythrocyte plasma membrane fluidity and a decrease in the in-plane mobility of heme pyrrole rings in membranebound $\mathrm{Hb}$ under hypertension, which may affect the affinity of hemoglobin to oxygen. The proposed SERS-based approach may be used to develop novel diagnostic tools to detect early pathologies and to assess treatment outcomes in CVD and beyond.

Supplementary Materials: The following supporting information can be downloaded at: https: / / www.mdpi.com/article/10.3390/bios12010032/s1, Figure S1: (a) SERS spectra of erythrocyte ghosts recorded from different places in a randomly chosen AgNSS. X-axis, Raman shift, $\mathrm{cm}^{-1}$; Y-axis, SERS intensity, vertical scale bar corresponds to 1000 arbitr.u. For a clearer representation, the spectra are shifted vertically. Numbers above a peak show maximum positions. The similarity of the spectral structure demonstrates the high reproducibility of the SERS spectra of erythrocyte ghosts. (b) Raman and SERS spectra of erythrocyte suspensions. X-axis, Raman shift, $\mathrm{cm}^{-1}$; Y-axis, Raman or SERS intensity. Raman spectrum (black) was recorded from the erythrocyte suspension obtained by a 50-time blood dilution; SERS spectrum (red) was recorded from an erythrocyte sample obtained by a 2000-time blood dilution. Laser wavelength was $514 \mathrm{~nm}$ with a power of $1 \mathrm{~mW}$ per registration spot, with 60 s accumulation time; objective 20x, NA 0.4 .

Author Contributions: Conceptualization: N.A.B., E.I.N., G.V.M. and O.S. conceived the experiments. N.A.B. and E.I.N. performed SERS experiments and analyzed SERS spectra. A.A.S., E.A.G. and E.I.N. fabricated AgNSS. N.A.B., E.I.N., A.A.B. and Z.V.B. prepared samples. E.I.N., Z.V.B. and A.A.B. measured the parameters of animals. A.A.S. and E.A.G. performed the electron microscopy (SEM) analysis. V.S.V., D.I.Y., S.M.N. and A.V.A. performed SNOM characterization. N.A.B., G.V.M., E.A.G. and O.S. contributed tools and materials. N.A.B. supervised the project. N.A.B., E.I.N., S.M.N. and O.S. drafted the manuscript. All authors discussed the results and edited and commented on the manuscript. All authors have read and agreed to the published version of the manuscript. 
Funding: E.I.N. and Z.V.B. acknowledge support from Russian Science Foundation for SERS experiments and preparations (RSF, grant number 21-74-00026). s-SNOM studies were funded by the Ministry of Science and Higher Education of the Russian Federation (Agreement No. 075-15-2021606) and the Russian Foundation for Basic Research (20-07-00475). A.A.S. thanks the Russian Science Foundation for the support used for AgNSS synthesis and SEM characterization (RSF, grant number 20-73-00257). N.A.B. acknowledges support from the Russian Foundation for Basic Research used for the development and the optimization of the Pyraman software for the spectrum analysis (RFBR, grant number 20-04-01011 a). This research has been partially supported by the Interdisciplinary Scientific and Educational School of Moscow University "Molecular Technologies of the Living Systems and Synthetic Biology".

Institutional Review Board Statement: The study was conducted according to the guidelines of the Declaration of Helsinki and approved by the Bioethics Committee of Moscow State University (protocol №82-O, 08.06.2017).

Informed Consent Statement: Not applicable.

Data Availability Statement: The data presented in this study are available on request from the corresponding author.

Acknowledgments: The authors acknowledge Artemieva Marina M. for help with the animal study.

Conflicts of Interest: The authors declare no conflict of interest.

\section{References}

1. Ganau, L.; Prisco, L.; Ligarotti, G.; Ambu, R.; Ganau, M. Understanding the Pathological Basis of Neurological Diseases Through Diagnostic Platforms Based on Innovations in Biomedical Engineering: New Concepts and Theranostics Perspectives. Medicines 2018, 5, 22. [CrossRef]

2. Beverung, S.; Wu, J.; Steward, R. Lab-on-a-chip for cardiovascular physiology and pathology. Micromachines 2020, 11, 898. [CrossRef]

3. Valpapuram, I.; Candeloro, P.; Coluccio, M.L.; Parrotta, E.I.; Giugni, A.; Das, G.; Cuda, G.; Di Fabrizio, E.; Perozziello, G. Waveguiding and SERS simplified Raman spectroscopy on biological samples. Biosensors 2019, 9, 37. [CrossRef]

4. Pires, P.W.; Dams Ramos, C.M.; Matin, N.; Dorrance, A.M. The effects of hypertension on the cerebral circulation. Am. J. Physiol. Circ. Physiol. 2013, 304, H1598-H1614. [CrossRef]

5. Zhou, W.; Brown, J.M.; Bajaj, N.S.; Chandra, A.; Divakaran, S.; Weber, B.; Bibbo, C.F.; Hainer, J.; Taqueti, V.R.; Dorbala, S.; et al. Hypertensive coronary microvascular dysfunction: A subclinical marker of end organ damage and heart failure. Eur. Heart, J. 2020, 41, 2366-2375. [CrossRef] [PubMed]

6. Semenza, G.L. Oxygen sensing, hypoxia-inducible factors, and disease pathophysiology. Annu. Rev. Pathol. Mech. Dis. 2014, 9, 47-71. [CrossRef]

7. Verbrugge, F.H.; Guazzi, M.; Testani, J.M.; Borlaug, B.A. Altered Hemodynamics and End-Organ Damage in Heart Failure. Circulation 2020, 142, 998-1012. [CrossRef]

8. Böning, D.; Kuebler, W.M.; Bloch, W. The oxygen dissociation curve of blood in COVID-19. Am. J. Physiol.-Lung Cell. Mol. Physiol. 2021, 321, L349-L357. [CrossRef] [PubMed]

9. Yudin, J.; Verhovsek, M. How we diagnose and manage altered oxygen affinity hemoglobin variants. Am. J. Hematol. 2019, 94, 597-603. [CrossRef] [PubMed]

10. Smolsky, J.; Kaur, S.; Hayashi, C.; Batra, S.K.; Krasnoslobodtsev, A.V. Surface-enhanced raman scattering-based immunoassay technologies for detection of disease biomarkers. Biosensors 2017, 7, 7. [CrossRef]

11. Pilot, R.; Signorini, R.; Durante, C.; Orian, L.; Bhamidipati, M.; Fabris, L. A review on surface-enhanced Raman scattering. Biosensors 2019, 9, 57. [CrossRef]

12. Brazhe, N.A.; Abdali, S.; Brazhe, A.R.; Luneva, O.G.; Bryzgalova, N.Y.; Parshina, E.Y.; Sosnovtseva, O.V.; Maksimov, G.V. New Insight into Erythrocyte through In Vivo Surface-Enhanced Raman Spectroscopy. Biophys. J. 2009, 97, 3206-3214. [CrossRef]

13. Semenova, A.A.; Goodilin, E.A.; Brazhe, N.A.; Ivanov, V.K.; Baranchikov, A.E.; Lebedev, V.A.; Goldt, A.E.; Sosnovtseva, O.V.; Savilov, S.V.; Egorov, A.V.; et al. Planar SERS nanostructures with stochastic silver ring morphology for biosensor chips. J. Mater. Chem. 2012, 22, 24530-24544. [CrossRef]

14. Sarycheva, A.S.; Brazhe, N.A.; Baizhumanov, A.A.; Nikelshparg, E.I.; Semenova, A.A.; Garshev, A.V.; Baranchikov, A.E.; Ivanov, V.K.; Maksimov, G.V.; Sosnovtseva, O.; et al. New nanocomposites for SERS studies of living cells and mitochondria. J. Mater. Chem. B 2016, 4, 539-546. [CrossRef]

15. Nikelshparg, E.I.; Grivennikova, V.G.; Baizhumanov, A.A.; Semenova, A.A.; Sosnovtseva, V.; Goodilin, E.A.; Maksimov, G.V.; Brazhe, N.A. Probing lipids in biological membranes using SERS. Mendeleev Commun. 2019, 29, 635-637. [CrossRef]

16. Sharma, R.; Premachandra, B.R. Membrane-bound hemoglobin as a marker of oxidative injury in adult and neonatal red blood cells. Biochem. Med. Metab. Biol. 1991, 46, 33-44. [CrossRef] 
17. Chu, H.; McKenna, M.M.; Krump, N.A.; Zheng, S.; Mendelsohn, L.; Thein, S.L.; Garrett, L.J.; Bodine, D.M.; Low, P.S. Reversible binding of hemoglobin to band 3 constitutes the molecular switch that mediates $\mathrm{O} 2$ regulation of erythrocyte properties. Blood 2016, 128, 2708-2716. [CrossRef] [PubMed]

18. Brazhe, N.A.; Evlyukhin, A.B.; Goodilin, E.A.; Semenova, A.A.; Novikov, S.M.; Bozhevolnyi, S.I.; Chichkov, B.N.; Sarycheva, A.S.; Baizhumanov, A.A.; Nikelshparg, E.I.; et al. Probing cytochrome c in living mitochondria with surface-enhanced Raman spectroscopy. Sci. Rep. 2015, 5, 1-13. [CrossRef]

19. Yamakoshi, K.I.; Kamiya, A. Noninvasive measurement of arterial blood pressure and elastic properties using photoelectric plethysmography technique. Med. Prog. Technol. 1987, 12, 123-143. [CrossRef]

20. Brazhe, N.A.; Parshina, E.Y.; Khabatova, V.V.; Semenova, A.A.; Brazhe, A.R.; Yusipovich, A.I.; Sarycheva, A.S.; Churin, A.A.; Goodilin, E.A.; Maksimov, G.V.; et al. Tuning SERS for living erythrocytes: Focus on nanoparticle size and plasmon resonance position. J. Raman Spectrosc. 2013, 44, 686-694. [CrossRef]

21. Bukara, K.; Jovanić, S.Z.; Drvenica, I.T.; Stančić, A.; Ilić, V.; Rabasović, M.D.; Pantelić, D.V.; Jelenković, B.M.; Bugarski, B.; Krmpot, A.J. Mapping of hemoglobin in erythrocytes and erythrocyte ghosts using two photon excitation fluorescence microscopy. $J$. Biomed. Opt. 2017, 22, 026003. [CrossRef]

22. Shiohara, A.; Novikov, S.M.; Solís, D.M.; Taboada, J.M.; Obelleiro, F.; Liz-Marzán, L.M. Plasmon Modes and Hot Spots in Gold Nanostar-Satellite Clusters. J. Phys. Chem. C 2015, 119, 10836-10843. [CrossRef]

23. Moskovits, M. Spot the hotspot. Nature 2011, 469, 307-308. [CrossRef] [PubMed]

24. Zenin, V.A.; Andryieuski, A.; Malureanu, R.; Radko, I.P.; Volkov, V.S.; Gramotnev, D.K.; Lavrinenko, A.V.; Bozhevolnyi, S.I. Boosting Local Field Enhancement by on-Chip Nanofocusing and Impedance-Matched Plasmonic Antennas. Nano Lett. 2015, 15, 8148-8154. [CrossRef]

25. Novikov, S.M.; Frydendahl, C.; Beermann, J.; Zenin, V.A.; Stenger, N.; Coello, V.; Mortensen, N.A.; Bozhevolnyi, S.I. White Light Generation and Anisotropic Damage in Gold Films near Percolation Threshold. ACS Photonics 2017, 4, 1207-1215. [CrossRef]

26. Bozhevolnyi, S.I.; Volkov, V.S.; Leosson, K.; Boltasseva, A. Bend loss in surface plasmon polariton band-gap structures. Appl. Phys. Lett. 2001, 79, 1076-1078. [CrossRef]

27. Torres Filho, I.P.; Terner, J.; Pittman, R.N.; Proffitt, E.; Ward, K.R. Measurement of hemoglobin oxygen saturation using Raman microspectroscopy and 532-nm excitation. J. Appl. Physiol. 2008, 104, 1809-1817. [CrossRef] [PubMed]

28. Atkins, C.G.; Buckley, K.; Blades, M.W.; Turner, R.F.B. Raman Spectroscopy of Blood and Blood Components. Appl. Spectrosc. 2017, 71, 767-793. [CrossRef]

29. Gautam, R.; Oh, J.Y.; Marques, M.B.; Dluhy, R.A.; Patel, R.P. Characterization of storage-induced red blood cell hemolysis using Raman spectroscopy. Lab. Med. 2018, 49, 298-310. [CrossRef]

30. Senge, M.O.; MacGowan, S.A.; O'Brien, J.M. Conformational control of cofactors in nature-the influence of protein-induced macrocycle distortion on the biological function of tetrapyrroles. Chem. Commun. 2015, 51, 17031-17063. [CrossRef]

31. Kinschel, D.; Bacellar, C.; Cannelli, O.; Sorokin, B.; Katayama, T.; Mancini, G.F.; Rouxel, J.R.; Obara, Y.; Nishitani, J.; Ito, H.; et al. Femtosecond $X$-ray emission study of the spin cross-over dynamics in haem proteins. Nat. Commun. 2020, 11, 1-8. [CrossRef]

32. Perutz, M.F.; Wilkinson, A.J.; Paoli, M.; Dodson, G.G. The stereochemical mechanism of the cooperative effects in hemoglobin revisited. Annu. Rev. Biophys. Biomol. Struct. 1998, 27, 1-34. [CrossRef] [PubMed]

33. Brazhe, N.A.; Nikelshparg, E.I.; Baizhumanov, A.A.; Grivennikova, V.G.; Semenova, A.A.; Novikov, S.M.; Volkov, V.S.; Arsenin, A.V.; Yakubovsky, D.I.; Evlyukhin, A.B.; et al. SERS uncovers the link between conformation of cytochrome c heme and mitochondrial membrane potential. bioRxiv 2021, 1-33. [CrossRef]

34. Chertkova, R.V.; Brazhe, N.A.; Bryantseva, T.V.; Nekrasov, A.N.; Dolgikh, D.A.; Yusipovich, A.I.; Sosnovtseva, O.; Maksimov, G.V.; Rubin, A.B.; Kirpichnikov, M.P. New insight into the mechanism of mitochondrial cytochrome c function. PLoS ONE 2017, 12, e0178280. [CrossRef] [PubMed]

35. Czamara, K.; Majzner, K.; Pacia, M.Z.; Kochan, K.; Kaczor, A.; Baranska, M. Raman spectroscopy of lipids: A review. J. Raman Spectrosc. 2015, 46, 4-20. [CrossRef]

36. Kutuzov, N.P.; Brazhe, A.R.; Yusipovich, A.I.; Maksimov, G.V.; Dracheva, O.E.; Lyaskovskiy, V.L.; Bulygin, F.V.; Rubin, A.B. ATP-induced lipid membrane reordering in the myelinated nerve fiber identified using Raman spectroscopy. Laser Phys. Lett. 2013, 10, 075606. [CrossRef]

37. Shvalya, V.; Filipič, G.; Zavašnik, J.; Abdulhalim, I.; Cvelbar, U. Surface-enhanced Raman spectroscopy for chemical and biological sensing using nanoplasmonics: The relevance of interparticle spacing and surface morphology. Appl. Phys. Rev. 2020, 7, 031307. [CrossRef]

38. Luneva, O.G.; Brazhe, N.A.; Maksimova, N.V.; Rodnenkov, O.V.; Parshina, E.Y.; Bryzgalova, N.Y.; Maksimov, G.V.; Rubin, A.B.; Orlov, S.N.; Chazov, E.I. Ion transport, membrane fluidity and haemoglobin conformation in erythrocyte from patients with cardiovascular diseases: Role of augmented plasma cholesterol. Pathophysiology 2007, 14, 41-46. [CrossRef] [PubMed]

39. Yusipovich, A.I.; Braze, N.A.; Luneva, O.G.; Parshina, E.Y.; Churin, A.A.; Rodnenkov, O.V.; Maksimov, G.V. Changes in the state of hemoglobin in patients with coronary heart disease and patients with circulatory failure. Bull. Exp. Biol. Med. 2013, 155, 233-235. [CrossRef] [PubMed]

40. Tziakas, D.N.; Kaski, J.C.; Chalikias, G.K.; Romero, C.; Fredericks, S.; Tentes, I.K.; Kortsaris, A.X.; Hatseras, D.I.; Holt, D.W. Total Cholesterol Content of Erythrocyte Membranes Is Increased in Patients With Acute Coronary Syndrome. A New Marker of Clinical Instability? J. Am. Coll. Cardiol. 2007, 49, 2081-2089. [CrossRef] [PubMed] 
41. Zhong, Y.; Tang, H.; Zeng, Q.; Wang, X.; Yi, G.; Meng, K.; Mao, Y.; Mao, X. Total cholesterol content of erythrocyte membranes is associated with the severity of coronary artery disease and the therapeutic effect of rosuvastatin. Ups. J. Med. Sci. 2012, 117, 390-398. [CrossRef] [PubMed]

42. Khatibzadeh, N.; Gupta, S.; Farrell, B.; Brownell, W.E.; Anvari, B. Effects of cholesterol on nano-mechanical properties of the living cell plasma membrane. Soft Matter 2012, 8, 8350-8360. [CrossRef] [PubMed]

43. Ayee, M.A.; Levitan, I. Paradoxical impact of cholesterol on lipid packing and cell stiffness. Front. Biosci. - Landmark 2016, 21, 1245-1259. [CrossRef]

44. Forsyth, A.M.; Braunmüller, S.; Wan, J.; Franke, T.; Stone, H.A. The effects of membrane cholesterol and simvastatin on red blood cell deformability and ATP release. Microvasc. Res. 2012, 83, 347-351. [CrossRef] [PubMed]

45. Faried, M.; Suga, K.; Okamoto, Y.; Shameli, K.; Miyake, M.; Umakoshi, H. Membrane Surface-Enhanced Raman Spectroscopy for Cholesterol-Modified Lipid Systems: Effect of Gold Nanoparticle Size. ACS Omega 2019, 4, 13687-13695. [CrossRef]

46. Yao, J.; Wang, L.; Yang, J.M.; Maslov, K.I.; Wong, T.T.W.; Li, L.; Huang, C.H.; Zou, J.; Wang, L.V. High-speed label-free functional photoacoustic microscopy of mouse brain in action. Nat. Methods 2015, 12, 407-410. [CrossRef]

47. Nolfi-Donegan, D.; Braganza, A.; Shiva, S. Mitochondrial electron transport chain: Oxidative phosphorylation, oxidant production, and methods of measurement. Redox Biol. 2020, 37, 101674. [CrossRef]

48. De Vecchis, D.; Reithmeier, R.A.F.; Kalli, A.C. Molecular Simulations of Intact Anion Exchanger 1 Reveal Specific Domain and Lipid Interactions. Biophys. J. 2019, 117, 1364-1379. [CrossRef] 